\section{New products and focus on cosmetic dentistry}

\section{NEW PROFESSIONAL WEBSITE LAUNCHED}

Colgate has developed a new website for UK dental professionals that provides information and resources to support your practice. On registering at www.colgateprofessional.co.uk, the entire website will become your own personalised professional site. Each time you return and log in, your home page will have a wide range of resources available to you. Available on the site are educational materials for patients such as images, videos and interactive tools to help them learn more about specific conditions.

To browse the complete library of educational materials, select a topic, and the type of content you would like to see. Once you have selected the materials you can easily add your practice name and logo to create custom emails and printed materials for your patients. Alternatively, you may like to include links directly on your own practice website. All the materials you review and/or customise can be added to a 'favourites'

\section{NON-RUNNING FORMULA}

GC's Gradia Direct Flo flowable composite can be used in conjunction with Gradia Direct and the shades are a perfect match to the colour concept of this easy to use and aesthetic composite.

Due to its physical properties and flow characteristics it can be used as a liner, for blocking undercuts under composite restorations and for minimal intervention cavities.

Gradia Direct Flo's non-running and non-stick formula shapes to cavity walls and makes it easy to handle. This radiopaque material folder ready for use with other patients.

In Colgate's library of continuing professional development (CPD) you can choose from the CPD topic list and click 'play' for a five minute preview of your chosen programme, then click on the icon to download the complete file. This section will also direct you to other CPD programmes that may be of interest to you.

Colgate supports continued development, education and training for dental professionals through research prizes and award opportunities. View the Research Prizes \& Awards section to see the various opportunities available. Additionally, in this section you can view a schedule of forthcoming UK events and meetings showing the date, location and website link for each.

You can also see the company's product range by indication type, which includes caries, dentine hypersensitivity and periodontitis. Alternatively, you

is supplied in a syringe design that allows for easy manipulation and precise application. It is available in seven shades: A1, A2, A3, A3.5, A03, $\mathrm{CV}$ and BW.

Reader response number 51

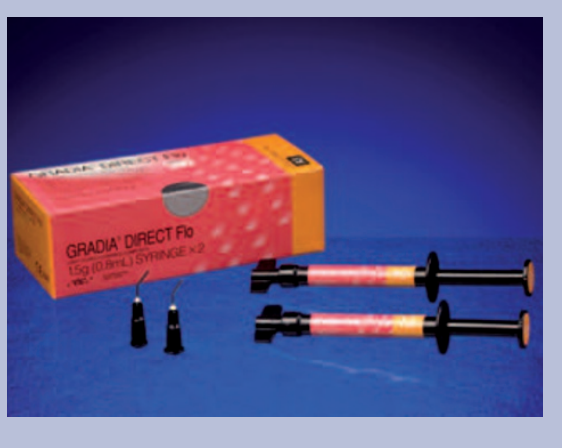

Please send trade news information and illustrations to Arveen Bajaj at the BDJ, Nature Publishing Group, The Macmillan Building, 4-6 Crinan Street, London N1 9XW. Trade news is provided as a service to readers using text and images from the manufacturer, supplier or distributor and does not imply endorsement by the $B D J$. Normal and prudent research should be exercised before purchase or use of any product mentioned.

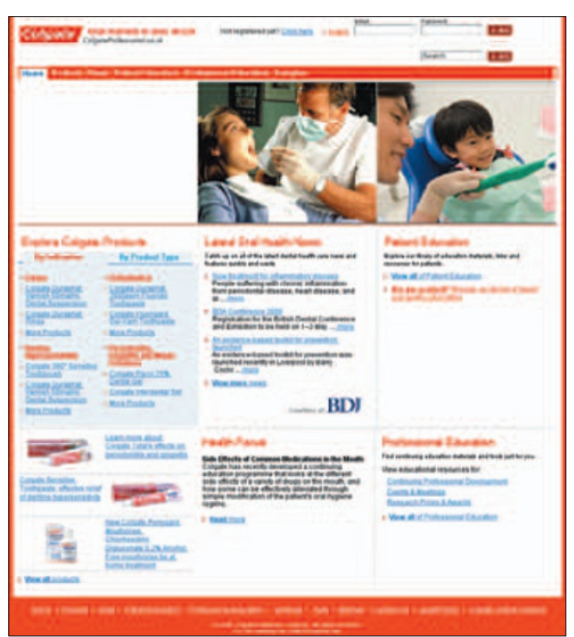

can view by product type to learn more about individual products and review the supporting clinical evidence. Once you have logged in you will have the ability to request patient samples and literature. You can also receive the latest oral health news by having it delivered directly to your desktop via the link from the British Dental Journal.

Reader response number $\mathbf{5 0}$

\title{
FLUTED DRILLS FOR PRECISION
}

The new Predator AccuPrep tungsten carbide bur from Prima Dental Group delivers a faster, more efficient cut and better preparation surface.

While crown and bridge preparation has traditionally used diamond tipped burs, Prima has developed a parallel product with its tungsten carbide fluted drills. With the minimum of clogging for precision, the product matches the most popular diamond patterns, so you need not change your technique.

Reader response number 52 


\section{FREE ONLINE TRAINING FACILITY}

Sirona Cerec's new website is dedicated to ensuring customer satisfaction from before the moment of purchase. With a free online training facility the website at www.sironacadcamsolutions. co.uk allows you to more than visualise how restorations can be created in the comfort of your own surgery.

Get to know the system quickly and learn how to market Cerec to your patients and see actual cases in your home or at the practice, from the most simple procedures to more advanced cases. Reader response number 53

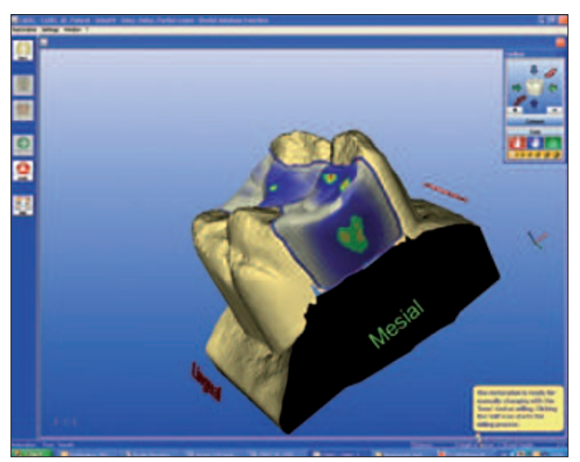

\section{FINDING SUCCESSFUL COMMUNICATION STRATEGIES}

Communications in Dentistry: Stories from the Practice is a modular CD-ROM series produced by Smile-on in collaboration with Dental Protection. The second and third parts of the series focus on 'Communicating with your patients' and 'Communicating with your team' and illustrate effective and not so effective communication styles and techniques by following the Briar Patch Dental Practice over a typical year.

The programme reveals is that it is vital that every practice develops successful communication strategies in order to increase productivity, encourage interaction between employees and assist in building strong relationships and effective teams. Visitors to the recent BDTA Dental Showcase exhibition were invited to a screening of the new CDROM hosted by Stephen Hancocks and addressed by Kevin Lewis of Dental Protection and Noam Tamir of Smile-on.

Three hours of verifiable CPD is conferred on up to five participants, with CPD for additional viewers available. One module costs $£ 150$ whilst all three modules in the series cost $£ 300$, and the licence allows them to be viewed and used by the whole dental team in practice or accessed on a home PC.

Reader response number 54

\section{SAVE TIME WITH RUBBER DAMS}

Dentsply offers a range of rubber dam materials which can be used in restorative dentistry and the company can arrange for a demonstration by its representatives.

The use of a rubber dam not only saves time, but helps to maintain a clean and dry work field, allowing for a better bonding process with the new dental materials,

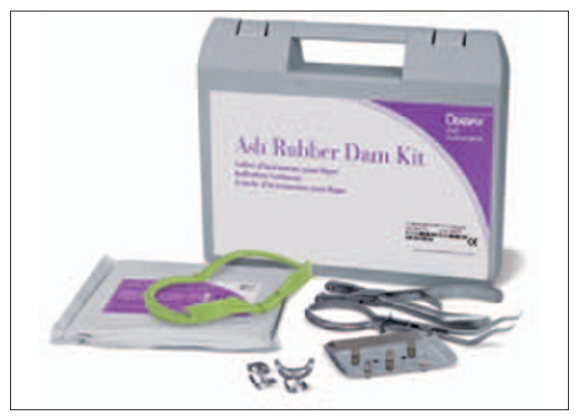

thereby creating stronger and longer lasting restorations.

Once correctly placed, patients appreciate not having fluid and debris building up at the back of their throats and genuinely feel more comfortable and relaxed. This in turn allows the dentist better access to the mouth.

Reader response number 56

\section{COSMETIC DENTISTRY ACCREDITATION}

The British Academy of Cosmetic Dentistry (BACD) is committed to the practice of cosmetic dentistry. They have recently introduced Accreditation, a non-compulsory method that demonstrates a particular level of competence reached by individuals.
Accredited Members will supply a 'gold-standard' service that reassures patients. The Accreditation accepts anonymous submission of clinical cases showing before and after pictures of those prepared by the candidate working independently.

\section{NEW COSMETIC IMAGING KIT LAUNCHED}

A new professional cosmetic imaging kit is now available from PracticeWorks. The kit includes everything needed for dental pictures including the software to prove how great a smile can look.

The Canon EOS 450D DSLR camera is ideal for dental photography and sor, new DIGIC III processor and 3.0' LCD display with live view.

The kit features a Canon EOS 450D DSLR camera body, Canon Selphy CP760 photographic printer, Photography Mirror and Cassette kit, two retractors, Kodak cosmetic imaging software and on-line training from start to finish. Also available is the compact Canon Selphy CP760 printer.

Reader response number 55

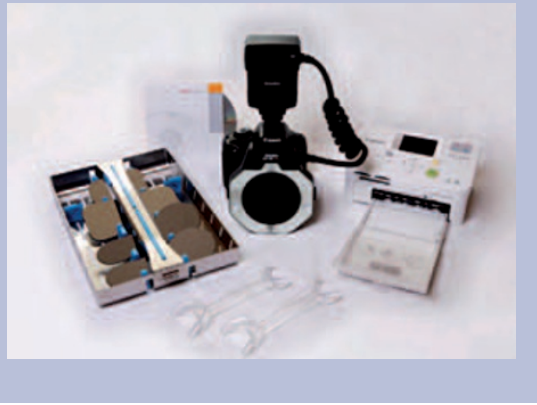

There is a Viva examination where candidates are asked to produce a treatment plan following a diagnosis; they are then asked questions from examiners about the chosen treatments and methods. For more information contact Suzy Rowlands on 02082418526 or emailsuzy@bacd.com.

Reader response number 57 


\section{WIRELESS WHITENING}

The WIS II from DMDS gives you the choice of fast and effective whitening, be it with LED or pulsation technology, from its easy to use portable, lightweight unit. The LED provides high concentration and quick whitening and the pulsation option is used for fast custom tray whitening.

Both provide swift, safe and effective long-term dual arch whitening in five to ten minutes. It is supplied with two pairs of safety glasses, four cheek retractors, whitening head, pulsation head, power adapter and complete instruction manual.

The WIS Light is not a UV light, but utilises the latest LED technology. This lessens the whitening time. With a 10- minute cycle, your patients' teeth can now be whitened in 20 minutes.

The WIS Light is portable as it is battery powered and the system efficiently uses rechargeable batteries, which can use a mains attachment to give greater flexibility. This cordless system allows the WIS Light to be quickly and easily wheeled into different surgeries within the practice. Reader response number 58

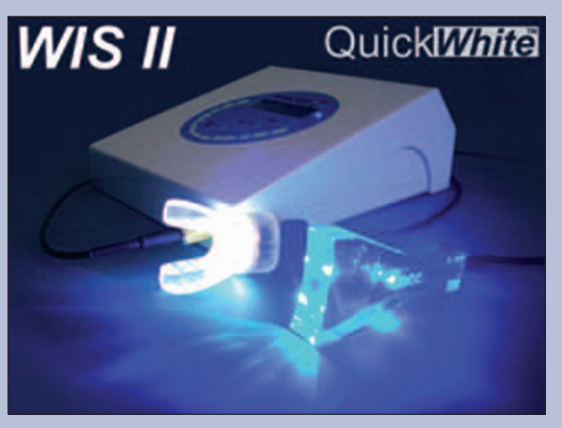

\section{FLUORIDE RELEASING, HIGH STRENGTH COMPOSITE}

Newly launched Beautifil II Gionomer from Shofu is a state of the art composite restorative material based on Pre-Reacted Glass Ionomer technology. This technology combines the benefits of glass ionomers with those of composite resins to produce a biocompatible, fluoride releasing, high strength, aesthetic material.

Due to the on-going release and recharge of the fluoride particles within Beautifil II, secondary caries is no longer a concern with the added benefit that plaque will not adhere to the surface of the restoration.

Saliva forms a material film on the surface of Beautifil II that is reported to minimise plaque adhesion and inhibit bacterial colonisation as an on-going process. The material takes on the colour of the surrounding tooth tissue. With a highly translucent finish this radiopaque versatile material exhibits wear resistance combined with a high filler load to ensure longevity of the final restoration.

To claim your free Beautifil II sample (without obligation, while stocks last), which includes $3 \times$ single dose A2, $3 \times$ single dose A3 and instructions for use, or for further information, please contact Shofu on 01892870800.

\section{Reader response number 59}

\section{IMPROVED COMPOSITE}

Nanotechnology is now available in the new Herculite XRV Ultra from Kerr. It is a nanohybrid composite that offers an aesthetic composite restorative for anterior and posterior use.

Herculite XRV Ultra is an extension in Kerr's composite line including the original Herculite XRV micro hybrid composite with proven performance.

Reader response number 60

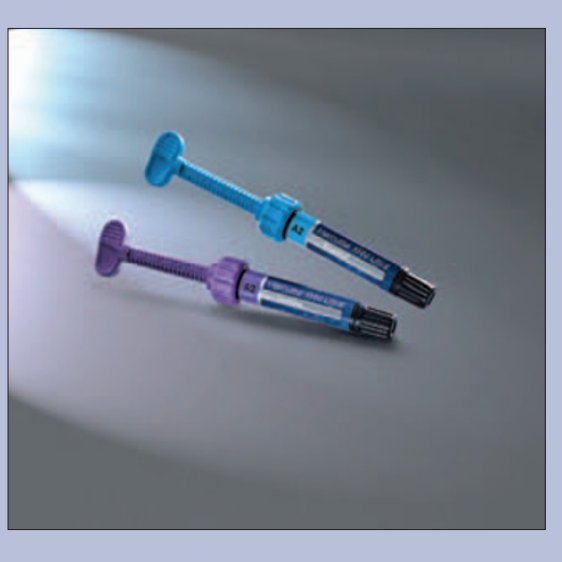

